\title{
The effects of exchange rate risk on economic performance: the Turkish experience
}

\section{Hakan Berument \& N. Nergiz Dincer}

To cite this article: Hakan Berument \& N. Nergiz Dincer (2004) The effects of exchange rate risk on economic performance: the Turkish experience, Applied Economics, 36:21, 2429-2441, DOI: $10.1080 / 0003684042000287637$

To link to this article: http://dx.doi.org/10.1080/0003684042000287637

册 Published online: 02 Feb 2007.

Submit your article to this journal

Џ Article views: 95

Q View related articles $\sqsubset$

4 Citing articles: 5 View citing articles ๘ 


\title{
The effects of exchange rate risk on economic performance: the Turkish experience $\dagger$
}

\author{
HAKAN BERUMENT* and N. NERGIZ DINCER: \\ Bilkent University, Department of Economics, Bilkent University, 06800 Ankara, \\ Turkey and $\$$ Bilkent University and State Planning Organization
}

This study examines the effects of real exchange rate risk on the economic performance for an emerging, small open economy: Turkey. When the ratios of the total foreign exchange liabilities of the Central Bank of the Republic of Turkey (CBRT) to: (1) total reserves; (2) the CBRT's reserves; and (3) the CBRT's total Turkish lira liabilities are taken proxy of exchange rate risk, the empirical evidence suggests that the increase in exchange rate risk causes a depreciation in the real exchange rate, an increase in prices and a decrease in output.

\section{INTRODUCTION}

The objective of policymakers is to lead their economies to a stable growth path. In order to avoid fluctuations in the overall economy, it is important to align various policy variables to stabilize the economy. This paper examines the effects of the exchange rate risk on macroeconomic variables using VAR models. The results of the models suggest that the exchange rate risk decreases output, increases inflation and causes depreciation for Turkey during the period February 1987 to September 2002.

This study is focused on Turkey, which is a developing small-open economy and is not under heavy government regulations. Therefore, it is possible to observe the effects of the financial markets on the real sector. Turkey has also suffered from high and persistent inflation without running hyperinflation, along with volatile growth pattern for almost three decades. This provides a unique environment for observing the interrelationships among certain macro- economic variables. This high inflation plays a magnifying role and allows one to avoid the type 2 error - not rejecting the null hypothesis even if the null is false.

The Central Bank of the Republic of Turkey (CBRT) considers the real exchange variability a threat to the stability of financial markets due to high dollarization and the vulnerability of the Turkish economy to current account crises (see Berument, forthcoming). However, even if the CBRT fully intends to stabilize the real exchange rate, the CBRT does not have complete control over the foreign exchange market. The CBRT can only stabilize the market with the tools that it has. Stabilizing the foreign exchange market is costly; thus, the CBRT may stabilize the market with the strength of its balance sheet. The stronger its balance sheet is, the stronger the policy implementation will be. Even if the CBRT does not take any action to stabilize the real exchange rate when it has a strong balance sheet, speculation or volatility will be lower since the speculators know that the CBRT has explicitly announced its concerns

$\dagger$ The views presented here are those of the authors; they do not necessarily reflect the official position of the State Planning Organization or its staff.

*Corresponding author. E-mail: berument@bilkent.edu.tr 
regarding the real exchange rate. Thus, the CBRT's Total Foreign Exchange (FX) liabilities were used as the indicator of the exchange rate risk. The higher the CBRT's FX liabilities, the less power the CBRT will have to stabilize the exchange rate and the higher the exchange rate risk will be. Even if the speculators are not active, the public will observe the CBRT's balance sheet and realize that if there is a shock to FX markets CBRT will be less willing to intervene in FX markets and currency will be more volatile.

To assess the effect of exchange rate risk on the economic performance, most of the literature concentrates on the commitment of fixed exchange rate regime as a proxy for exchange rate risk (see, for example, Agénor and Montiel, 1999; Chapter 7). However, under the influence of the CBRT, the value of the Turkish lira against major currencies is aligned daily, thus the real exchange rate is aligned continuously. This study analyses the effects of exchange rate risk on exchange rate, output and prices. A simple theoretical model that incorporates the effect of exchange rate risk on economic performance is also provided in Appendix A. To the best of knowledge, no study looks at the effect of exchange rate risk on output, prices and exchange rate simultaneously. In the literature, exchange rate volatility mostly assesses the effect of volatility on trade (see Cote, 1994 for a discussion of this literature). However, studies looking at other macroeconomic effects of exchange rate volatility are limited. Some of these stu- dies explain the effects of exchange rate volatility on bank stock returns (Tai, 2000), on interest rates (Berument and Gunay, 2003), and on investment and output (Bleaney and Greenaway, 2001). Felmingham and Mansfield (1997), however, examine the relationship between depreciation and exchange rate volatility. Their results suggest that depreciation creates uncertainty and the premium varies continuously until the market settles.

The contribution of this paper is two-fold. First, this is the only study that addresses the effect of exchange rate risk within a dynamic framework for output, prices and real exchange rate. Second, this paper assesses the effects of this relationship for a developing country. The remainder of the study is organized as follows: the next section explains the developments in the Turkish exchange rate. Section III discusses exchange rate risk measures. Section IV introduces the data used in the analyses. Section V discusses the analyses and the estimates and Section VI concludes.

\section{DEVELOPMENTS IN THE TURKISH EXCHANGE RATE}

In the 1980s, the government followed an exchange rate policy that aimed at preventing the real exchange rate from appreciating (Fig. 1), thereby supporting the export-

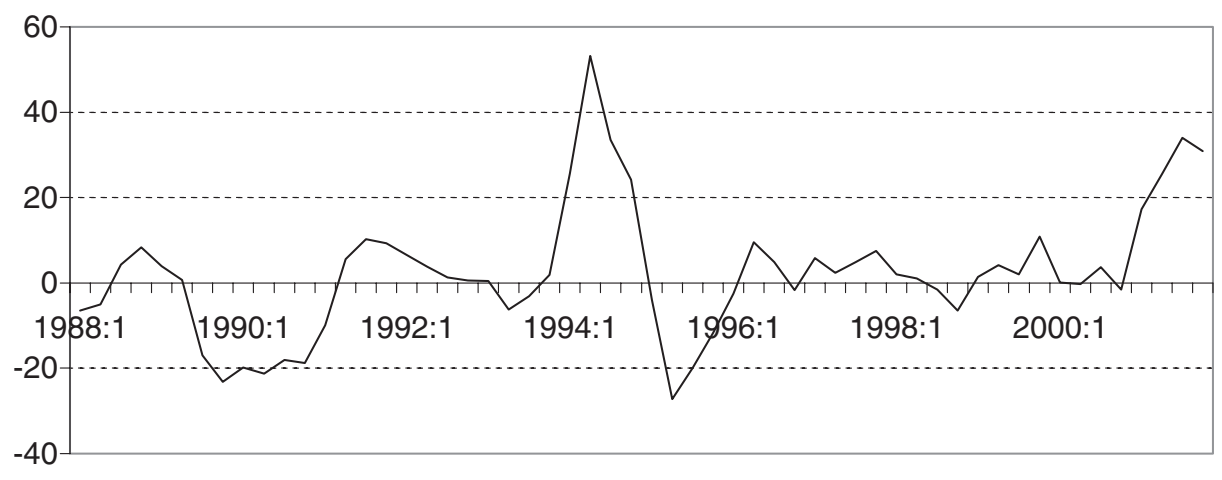

Fig. 1. Change in the real exchange rate $(\%, T L / \$)$

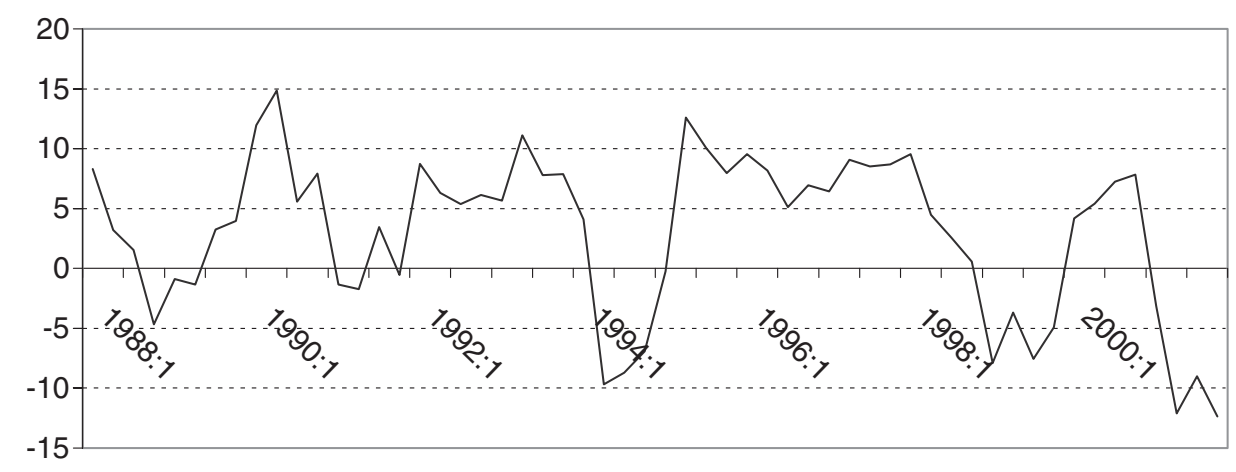

Fig. 2. Growth of the GNP (\%) 


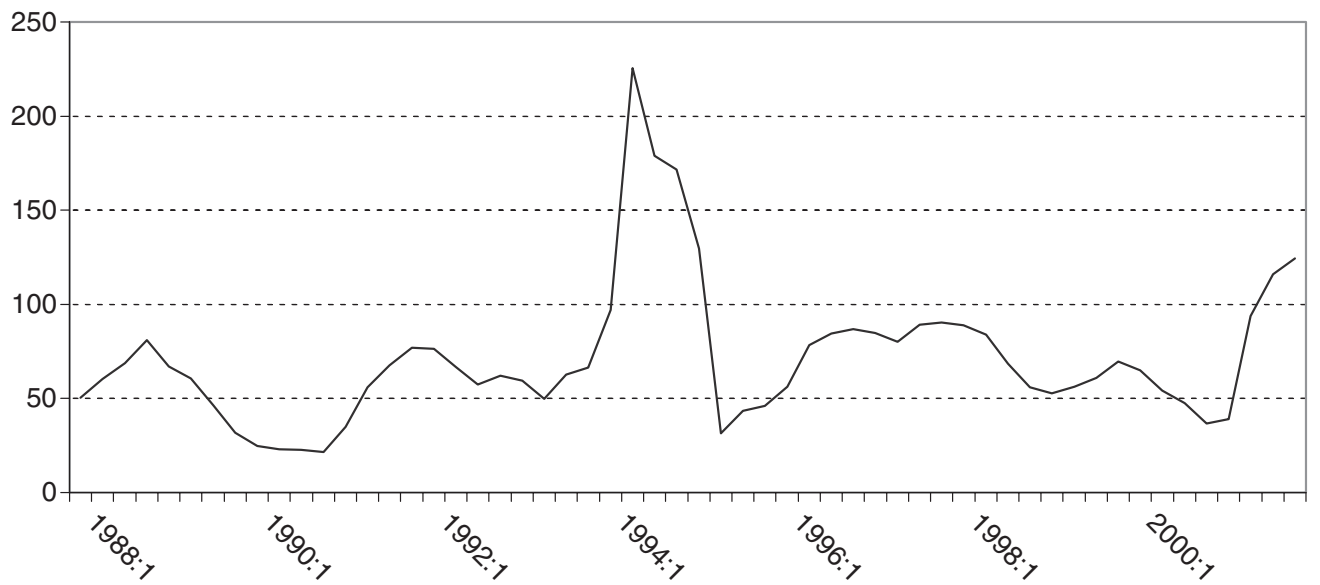

Fig. 3. Change in the nominal exchange rate $(\%, T L / \$)$

led growth strategy. As a result, the 1980s were the years of integration with the world economy for Turkey. Exports grew impressively and high growth rates were observed (Fig. 2).

The Central Bank of the Republic of Turkey (CBRT), announced daily quotations following the managed floating regime, and domestic currency was depreciated continuously parallel to inflation expectations considering the real exchange rate. In 1989, the capital account liberalized and in 1990, Turkey adopted a convertibility policy for the Turkish lira. High capital inflows that were realized in the 1988-1990 period caused the appreciation of the currency. Furthermore, the policy of the government was to support the value of the real exchange rate (preventing the exchange rate from depreciating). By 1990, to attract more capital inflows the CBRT increased interest rates. However, this policy led to further increases in the interest rate-exchange rate spread. During this period, a primary deficit was observed and the Public Sector Borrowing Requirements was financed with short-term domestic borrowing. With the increase in interest rates, domestic debt stock grew to such a level that a debt-roll over problem arose. Expectations for devaluation increased at the end of 1993. In January 1994, the CBRT abandoned the exchange rate policy and devalued the nominal exchange rate by 14\% (Figs 1 and 3). The devaluation of the currency continued until April 1994 and the total devaluation for this period reached $173 \%$ in nominal terms. Output declined by $6.2 \%$ in the same year (Fig. 2). In April 1994, a new programme to overcome the financial crises was brought into effect.

The Turkish economy recovered from the crisis quickly and the economy grew $8 \%$ in 1995 . With the increase in capital flows in 1996-1997, the capital account financed the current account. The increase in the central bank reserves and the loosening of the monetary policy contributed to the growth of investments and the economy. Inflation increased as well. The exchange rate policy after 1994 was designed to stabilize the real exchange rate. The CBRT depreciated the exchange rate parallel to inflation expectations.

In December 1999, Turkey adopted another disinflation programme with the support of the IMF. The aim of the programme was to decrease inflation to a single digit at the end of 2002. The exchange rate regime of the programme was announced as the crawling peg regime. The CBRT declared an exchange rate basket path consisting of $1 \mathrm{US} \$+0.77 €$, and announced a daily depreciation rate, which added up to a cumulative of $20 \%$ by the end of 2000.

The beginning of the programme gave positive signals. The nominal Treasury bond auction interest rates fell from $96.4 \%$ in November $1999^{1}$ to $34.1 \%$ in January 2000, inflation expectations decreased, high capital inflows were realized and the economy grew $4.8 \%$ in the first half of 2000 . However, with the high increase of imports, the current account deficit rose and that made the system fragile. As the real exchange rate appreciated with the programme, the banking sector increased its foreign currency denominated debt to a level that became risky for the system. With the sudden capital outflows in November 2000, banking sector crises occurred, which weakened the reserves of the CBRT by a significant amount. In February 2001, political instability triggered the mechanism and a severe crisis arose, and the crawling exchange rate regime was abandoned. The nominal exchange rate depreciated $94 \%$ (the annual increase of the second quarter of 2001) and the output response was detrimental, declining by $9.4 \%$ (Figs 2 and 3). The freely floating exchange rate regime was adopted then.

\footnotetext{
${ }^{1}$ There was no Treasury auction in December, 1999.
} 
In May 2001, a new programme based on floating exchange rate regime, tight fiscal policy and structural reforms was implemented. Signs of recovery were observed in 2002; output grew by $7.8 \%$.

Developments since 1987 show that Turkish economy experienced two severe crises that were followed by large devaluations. Different exchange rate regimes were implemented in different periods. However, none of the exchange rate regimes prevented the volatility of the value of the Turkish lira. The unexpected devaluations and the appreciations of the currency affected the economy; economic recessions were followed by large devaluations. Furthermore, appreciation of the currency caused problems, especially via the decrease in net exports, in the economy. Therefore, in order to stabilize the Turkish economy, which experienced high fluctuations in its currency, it is essential to understand the effects of exchange rate risk on the economy before designing new policies, which is the aim of this study.

\section{MEASURE OF EXCHANGE RATE RISK}

The focus of this study is to analyse the effects of exchange rate risk on the economy. How the risk is measured is an important point that should be elaborated on. In the literature, various methods are used to measure the exchange rate risk. One may calculate the risk by using a surveybased approach; the risk is measured by taking the standard deviation of forecasters (Hafer, 1986; Davis and Kanagoo, 1996, used this method to measure inflation uncertainty). However, Bomberger (1996) argues that using the dispersion of the survey forecast does not provide a measure of uncertainty, but rather a measure of disagreement. Furthermore, forecasters may try to avoid deviating from others' forecasts. This avoidance causes the value of expected value - hence the risk measure - to be biased.

Using Autoregressive Conditional Heteroscedastic models is another alternative for measuring the risk. This type of model specifies the conditional variance as a deterministic function of lagged squared residuals. Thus, this type of specification does not allow the uncertainty measure to be affected by the state of the economy, nor does it allow this measure to be entered in to a VAR specification directly to assess the dynamic relationship between the risk and economic performance. ${ }^{2}$
Kalman filtering could be used as another method to assess the risk. This method also allows the parameters in the exchange rate rules to be variable. Even if the exchange rate rule is not known by the public for the period considered, Kalman filtering generated variables are mostly exogenous to the public as set by the CBRT. Thus, it may not represent the public's perception of the exchange rate risk. Moreover, the perception is likely to be affected by the state of the economy or the power of the central bank to influence the exchange rate, but the Kalman filtering method does not allow for that.

However, in this paper these measures are not used to assess the exchange rate risk; instead, central bank balance sheet indicators are used, which reflect the CBRTs strength to affect the exchange rate volatility. These measures (1) can be observed by the public easily and (2) show that the CBRT has the power to align the exchange rate.

In this respect, the variables used as representative of the exchange rate risk in this study are ratios of the total foreign exchange liabilities of the CBRT, $F X L$, to central bank reserves; the ratio of FXL to total reserves, and the ratio of FXL to Turkish lira liabilities as measured by the variable Central Bank money. The reason for using these variables is that whenever these ratios increase, it becomes more difficult for the central bank to keep the domestic currency stable. This would be a negative signal for the market and exchange rate volatility would be likely to occur. Following Strongin (1995), in order to avoid double counting the Total Foreign Exchange Liabilities in both the nominator and denominator, we used the lag value of variables in the denominator. ${ }^{3}$

Table 1 presents the correlations between the variables that are gathered from the CBRTs balance sheet and the three-monthly moving standard errors of the real exchange rate. The results show that these variables are highly correlated with exchange rate volatility; therefore, these variables would be taken as a proxy for the exchange rate volatility.

\section{DATA}

The ratios of Foreign Exchange Liabilities of the CBRT to (1) Reserves; $F X L_{t} / R E S_{t-1}$ (2) Total Reserves; $F X L_{t} /$ $T_{R E S_{t-1}}$ and (3) the Central Bank money as a measure of Turkish lira liabilities, $F X L_{t} / T L L_{t-1}$ are taken as proxies of exchange rate risk. Then the real value of foreign

\footnotetext{
${ }^{2}$ Autoregressive Conditional Heteroscedastic specifications define the variability as a function of the lagged squared residuals but VAR specifications define the variability as a function of lagged dependent variables in the VAR system. Since both of them cannot be true at the same time, there is a specification problem if one uses an Autoregressive Conditional Heteroscedastic specification generated risk measure in a VAR setting.

${ }^{3}$ The basic results of the paper remains robust when the current value of the variables in the denominator are used.
} 
Table 1a. Cross correlations between real exchange rate volatility (as measured with moving standard deviation) and lags of exchange rate risk proxies

\begin{tabular}{lrrrrrrrrrrr}
\hline & \multicolumn{1}{c}{10} & \multicolumn{1}{c}{-9} & \multicolumn{1}{c}{-8} & \multicolumn{1}{c}{-7} & \multicolumn{1}{c}{-6} & \multicolumn{1}{c}{-5} & \multicolumn{1}{c}{-4} & -3 & -2 & -1 & 0 \\
\hline$F X L_{t} /$ RES $_{t-1}$ & -0.04 & -0.03 & -0.02 & -0.04 & -0.05 & -0.03 & 0.29 & 0.28 & 0.29 & 0.31 & 0.30 \\
$F X L_{t} /$ TRES $_{t-1}$ & 0.12 & 0.19 & 0.25 & 0.28 & 0.28 & 0.28 & 0.26 & 0.26 & 0.28 & 0.28 & 0.28 \\
$F X L_{t} /$ TLL $_{t-1}$ & -0.04 & -0.03 & -0.02 & -0.04 & -0.05 & -0.03 & -0.02 & -0.03 & 0.01 & 0.22 & 0.31 \\
\hline
\end{tabular}

Table 1b. Cross correlations between real exchange rate volatility (as measured with moving standard deviation) and leads of exchange rate risk proxies

\begin{tabular}{llllllllllll}
\hline & 0 & 1 & 2 & 3 & 4 & 5 & 6 & 7 & 8 & 9 \\
\hline$F X L_{t} /$ RES $_{t-1}$ & 0.30 & 0.27 & 0.24 & 0.22 & 0.21 & 0.06 & 0.02 & 0.01 & 0.33 & 0.16 & 0.15 \\
$F X L_{t} /$ TRES $_{t-1}$ & 0.28 & 0.26 & 0.23 & 0.21 & 0.19 & 0.18 & 0.17 & 0.16 & 0.16 & 0.14 & 0.13 \\
$F X L_{t} /$ TLL $_{t-1}$ & 0.31 & 0.13 & 0.13 & 0.04 & 0.06 & 0.02 & 0.01 & 0.07 & 0.16 & 0.15 & 0.11 \\
\hline
\end{tabular}

currency was taken as the real exchange rate; rer $_{t}$; output, $y_{t}$; and prices, $p_{t}$, by using monthly data covering the period from February 1987 to September 2002. All variables in this study are obtained from the CBRT's data delivery system (http://tcmbf40.tcmb.gov.tr/cbt.html). The variables that are used are constructed as follows: $F X L_{t} /$ $R E S_{t-1}$ is the ratio of the foreign exchange rate liabilities of the CBRT to the USD (denominated) reserves of the CBRT, whereas $F X L_{t} / T R E S_{t-1}$ is the ratio of the foreign exchange rate liabilities of the CBRT to the total USD (denominated) reserves. However, $F X L_{t} / T L L_{t-1}$ is the ratio of the foreign exchange rate liabilities of the CBRT to the Turkish Lira liabilities of the CBRT. The real exchange rate, $r r_{t}$, is calculated by deflating the basket (the basket is the TL value of 1 USD plus $1.5 \mathrm{DM})^{4}$ by the consumer price index. $y_{t}$ is the logarithm of the industrial production index; $p_{t}$ is the logarithm of the producer price index.

\section{ESTIMATES}

To observe the effects of exchange rate risk on the economy, three VAR models were specified with the variables representing exchange rate risk, $F X L_{t} / R E S_{t-1}, F X L_{t} \mid$ $T R E S_{t-1}$, and $F X L_{t} / T L L_{t-1}$ in each of the models, real exchange rate, output, and prices. A constant term, monthly dummies to account for seasonality, and US Treasury-bill 3-month interest rates were also added to account for the effects of the rest of the world. Based on the Bayesian information criterion the lag order of VAR was set as 2. To assess the effect of the exchange rate risk on the economic performance, a theoretically plausible model is presented in Appendix A.

In order to observe the effects, the variables representing exchange rate risk are put first in the ordering of each model. The exchange rate is expected to respond first to the risk. Output would then react to the change in the exchange rate and the exchange rate risk, therefore, it is put in the third place in the ordering. Finally, because they would react to changes in real exchange rates and output, prices are included at the end of the ordering.

\section{Impulse response functions}

The effects of shocks to the exchange rate risk are assessed by using impulse response functions. Figures 4 to 6 report the impulse response functions of different variables, which are highly correlated with exchange rate risk to the real exchange rate, output and prices when one standard deviation shock is given to the exchange rate risk measures. The $80 \%$ confidence bands are calculated using the bootstrap method with 500 draws and the middle line is for the median of the draws.

Figure 4 reports the impulse response functions of foreign exchange rate liabilities to Central Bank reserves, real exchange rate, output and prices. The second diagram shows that a positive shock to exchange rate risk causes real exchange rate depreciation for the whole period. For the first two months, the effect is higher; in other words, the initial effect is overshooting. In the long run, the real exchange rate stabilizes at a level that is higher than the initial one. The third diagram indicates that real output decreases as a response to a shock to exchange rate risk after the first month. After the second month, the effect on

\footnotetext{
${ }^{4}$ The central bank openly announced this as its target variable. By this construction, an increase in the exchange rate implies a depreciation.
} 
i. Response of $F X L_{t} / R E S_{t-1}$ to $F X L_{t} / R E S_{t-1}$

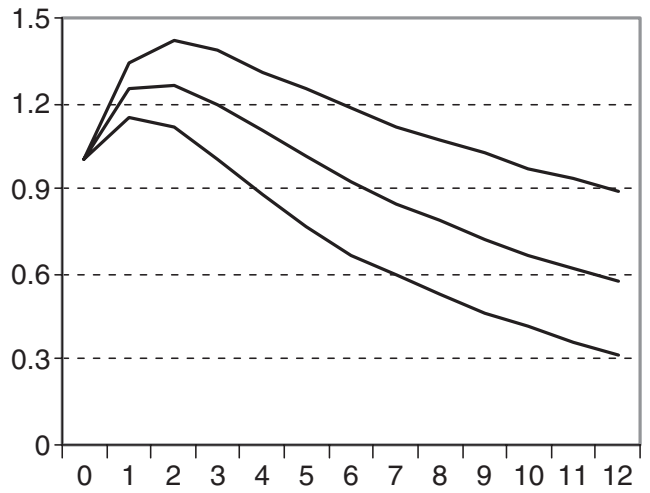

ii. Response of $r e r_{t}$ to $F X L_{t-1} / R E S_{t-1}$

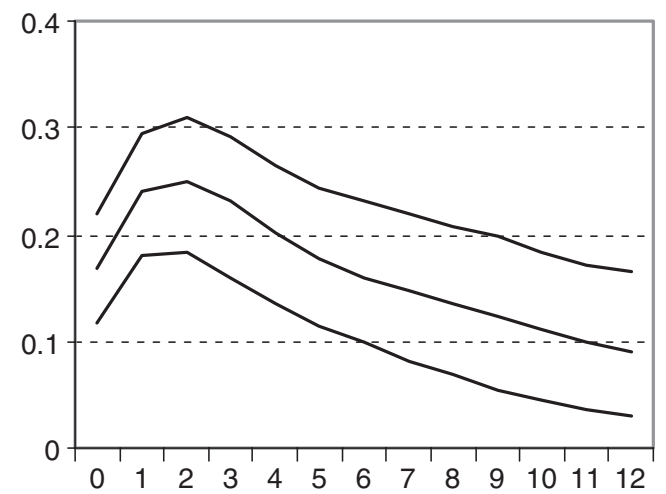

iii. Response of $y_{t}$ to $F X L_{t} / R E S_{t-1}$

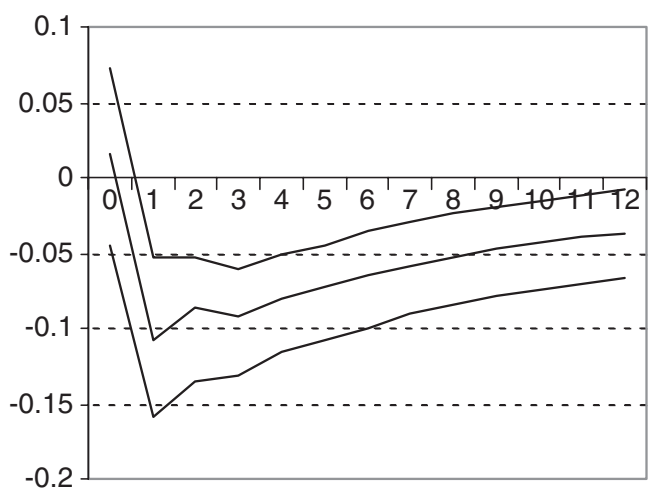

iv. Response of $p_{t}$ to $F X L_{t} / R E S_{t-1}$

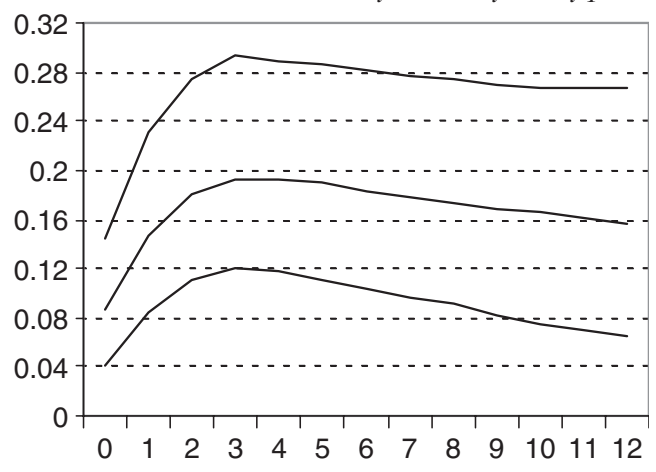

Fig. 4. Impulse response functions

output of a shock to the exchange rate risk starts to recover but remains lower than the initial level for the 12 months. As the last diagram presents, prices increase due to a positive shock to the exchange rate risk for the whole period. To sum up, the results show that a shock to the exchange rate risk causes real depreciation, decreases output and increases prices.

Figure 5 reports the impulse response functions of the foreign exchange rate liabilities to total reserves, the real exchange rate, output and prices. The estimates indicate that a positive shock to exchange rate risk causes a real depreciation for the whole period. For the first months, overshooting is observed but then the real exchange rate converges to its new long run level. The third diagram indicates that output decreases as a response to a positive shock to exchange rate risk and remains lower than the initial level for 12 months. On the other hand, prices increase after a positive shock to exchange rate risk is observed, and this effect persists.

Figure 6 reports the impulse response functions of foreign exchange liabilities to Central Bank money, the real exchange rate, output and prices. The figure indicates that the responses of the real exchange rate, output and prices to a shock to exchange rate risk are statistically insignificant.

\section{Forecast error variance decompositions}

In addition to the assessment of the dynamic effects of exchange rate risk shocks by using the impulse response functions, the forecast error variance decomposition analysis is also performed to examine how exchange rate risk shocks contribute to the variability of key economic aggregates.

Table 2 reports the forecast error variance decomposition of the macroeconomic variables due to $F X L_{t} / R E S_{t-1}$. On the left, the time horizons at which forecast errors are calculated are shown. The numbers in parentheses are standard errors. The results suggest that the shocks do contribute significantly to macroeconomic fluctuations, $30-40 \%$ of the variation in the real exchange rate, $12-19 \%$ of the variation in output and around $30 \%$ of the variation in prices is explained by the exchange rate risk variable.

In Table 3, FXL $/$ TRES $_{t-1}$ is used as a proxy for exchange rate risk and the forecast error variance decomposition of the macroeconomic variables due to this variable is reported. This set of estimates also suggests that the shocks contribute significantly to macroeconomic fluctuations. Although the contribution of exchange rate risk shocks to output is smaller, the basic results are robust. 


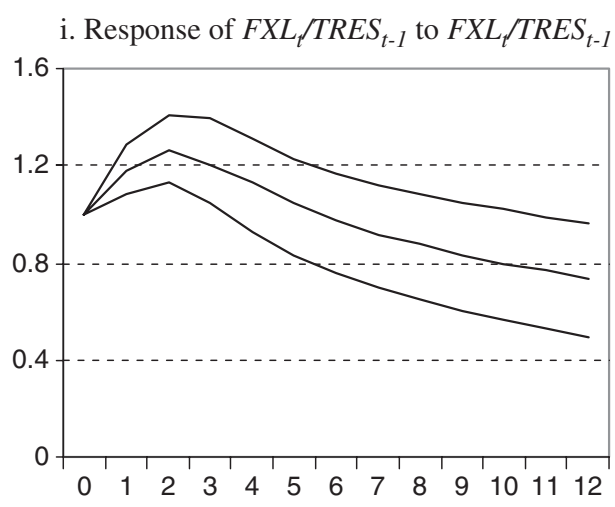

ii. Response of $r e r_{t}$ to $F X L_{t} / T R E S_{t-1}$

iii. Response of $y_{t}$ to $F X L_{t} / T R E S_{t-1}$

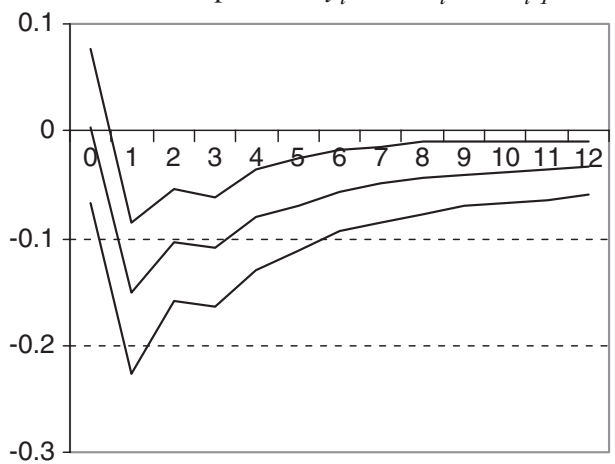

Fig. 5. Impulse response functions

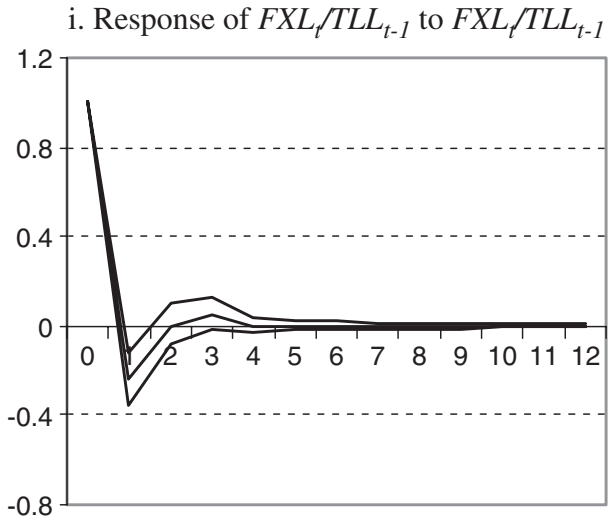

iii. Response of $y_{t}$ to $F X L_{t} / T L L_{t-1}$

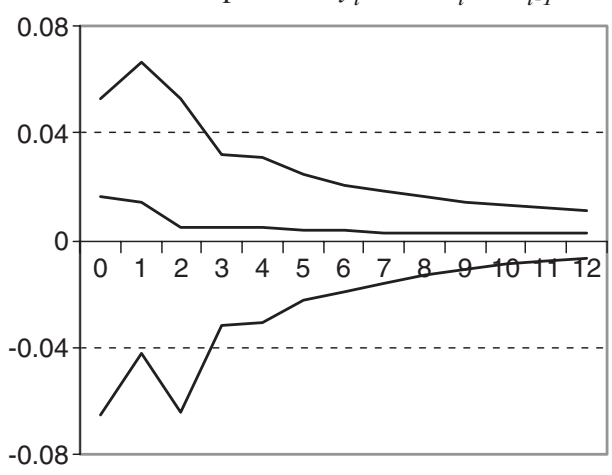

ii. Response of $r e r_{t}$ to $F X L_{t} / T L L_{t-1}$

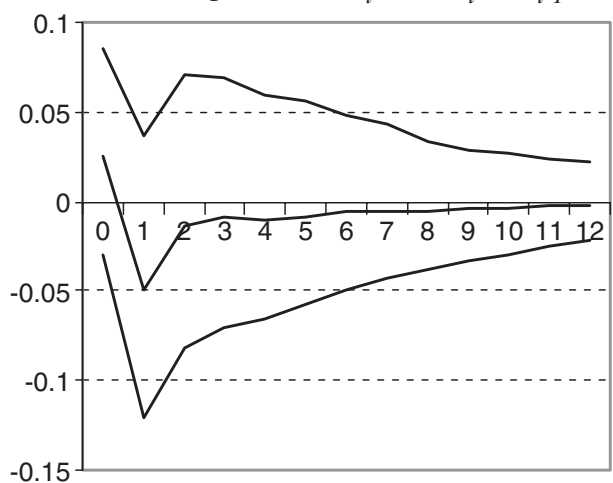

iv. Response of $p_{t}$ to $F X L_{t} / T L L_{t-1}$

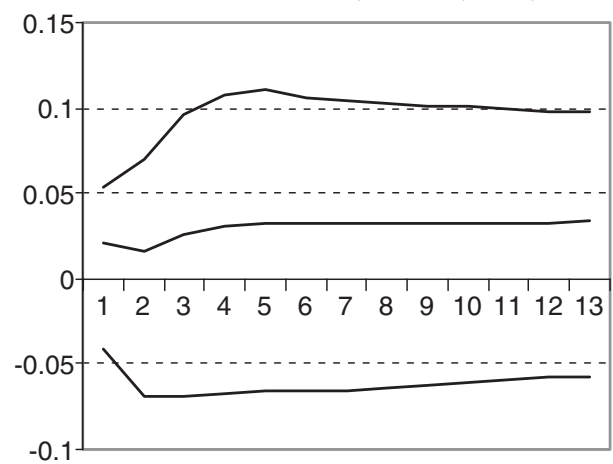

Fig. 6. Impulse response functions 
Table 2. Forecast error variance decompositions: contribution of $F X L_{t} / R E S_{t-1}$ to changes in key macroeconomic variables

\begin{tabular}{lllll}
\hline & $F X L_{t} /$ RES $_{t-1}$ & rer $_{t}$ & $y_{t}$ & $p_{t}$ \\
\hline Period 6 & $89 \%$ & $38 \%$ & $12 \%$ & $30 \%$ \\
& $(0.01)$ & $(0.09)$ & $(0.04)$ & $(0.08)$ \\
Period 12 & $92 \%$ & $43 \%$ & $17 \%$ & $29 \%$ \\
& $(0.01)$ & $(0.08)$ & $(0.04)$ & $(0.01)$ \\
Period 18 & $89 \%$ & $45 \%$ & $18 \%$ & $28 \%$ \\
& $(0.01)$ & $(0.06)$ & $(0.04)$ & $(0.13)$ \\
Period 24 & $87 \%$ & $44 \%$ & $19 \%$ & $26 \%$ \\
& $(0.02)$ & $(0.06)$ & $(0.03)$ & $(0.14)$ \\
\hline
\end{tabular}

Numbers in parentheses report the standard errors.
Table 3. Forecast error variance decompositions: contribution of $F X L_{t} / T_{R E S_{t-1}}$ to changes in key macroeconomic variables

\begin{tabular}{lllll}
\hline & FXL $_{t} /$ TRES $_{t-1}$ & rer $_{t}$ & $y_{t}$ & $p_{t}$ \\
\hline Period 6 & $92 \%$ & $43 \%$ & $9 \%$ & $42 \%$ \\
& $(0.02)$ & $(0.08)$ & $(0.05)$ & $(0.08)$ \\
Period 12 & $93 \%$ & $45 \%$ & $11 \%$ & $40 \%$ \\
& $(0.00)$ & $(0.06)$ & $(0.05)$ & $(0.09)$ \\
Period 18 & $93 \%$ & $46 \%$ & $12 \%$ & $38 \%$ \\
& $(0.01)$ & $(0.05)$ & $(0.05)$ & $(0.10)$ \\
Period 24 & $93 \%$ & $45 \%$ & $12 \%$ & $36 \%$ \\
& $(0.01)$ & $(0.05)$ & $(0.04)$ & $(0.10)$ \\
\hline
\end{tabular}

Numbers in parentheses report the standard errors. i. Response of volatility to volatility ${ }_{t}$

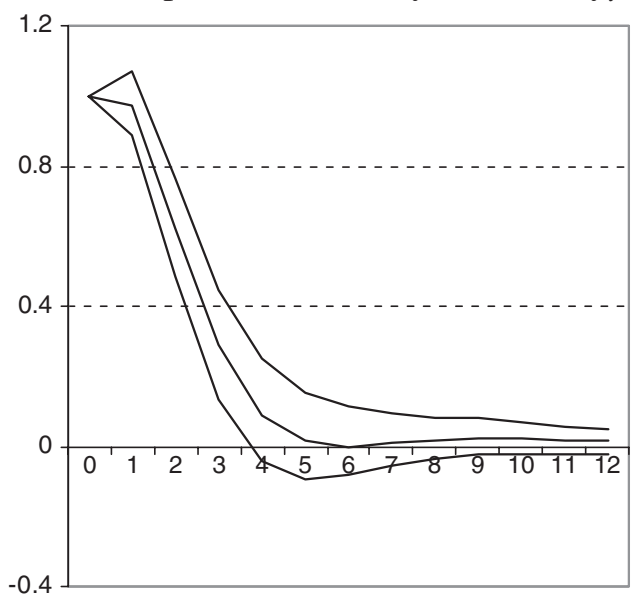

iii. Response of $y_{t}$ to volatility $y_{t}$

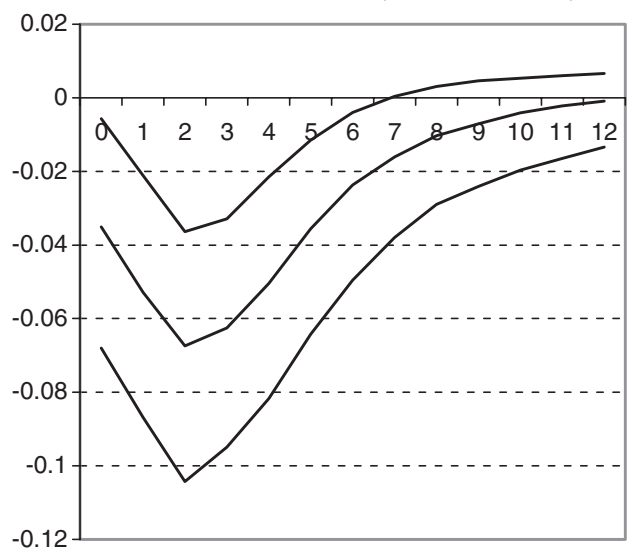

ii. Response tof $r e r_{t}$ to volatility

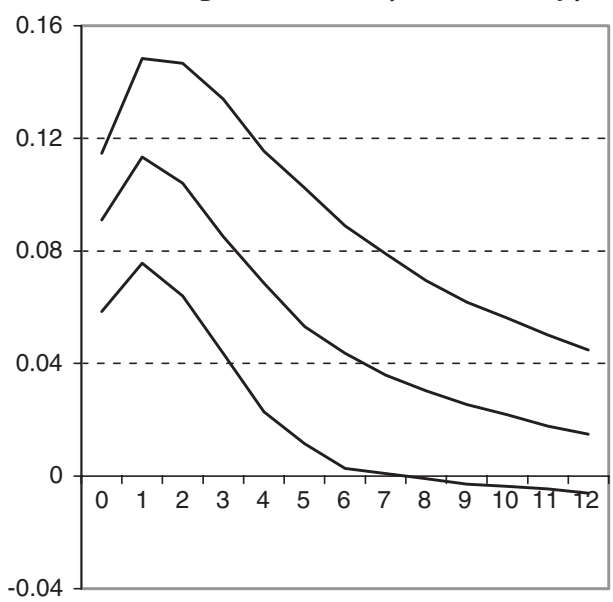

iv. Response of $p_{t}$ to volatility $y_{t}$

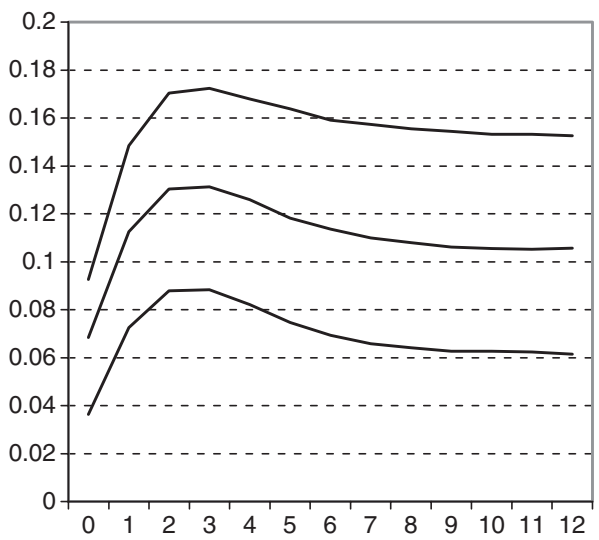

Fig. 7. Impulse response functions

Table 4 reports the forecast error variance decomposition of the macroeconomic variables due to exchange rate risk, which is taken as $F X L_{t} / T L L_{t-1}$. However, these results indicate that exchange rate risk shocks do not influence the fluctuations of real exchange rate, output and prices, even if the last set of the results on the effect of the exchange rate risk on economic performance is not robust. In all these specifications, the exchange rate risk measure is usually explained by itself, suggesting that this variable is mostly exogenous. 
Table 4. Forecast error variance decompositions: contribution of $F X L_{t} / T L L_{t-1}$ to changes in key macroeconomic variables

\begin{tabular}{lllll}
\hline & $F X L_{t} / T L L_{t-1}$ & rer $_{t}$ & $y_{t}$ & $p_{t}$ \\
\hline Period 6 & $78 \%$ & 0 & 0 & $1 \%$ \\
& $(0.06)$ & $(0.02)$ & $(0.02)$ & $(0.05)$ \\
Period 12 & $77 \%$ & 0 & 0 & $1 \%$ \\
& $(0.05)$ & $(0.02)$ & $(0.02)$ & $(0.06)$ \\
Period 18 & $77 \%$ & 0 & 0 & $1 \%$ \\
& $(0.06)$ & $(0.02)$ & $(0.02)$ & $(0.06)$ \\
Period 24 & $76 \%$ & 0 & 0 & $1 \%$ \\
& $(0.06)$ & $(0.02)$ & $(0.02)$ & $(0.06)$ \\
\hline
\end{tabular}

Numbers in parentheses report the standard errors.

Table 5. Forecast error variance decompositions: contribution of volatility to changes in key macroeconomic variables

\begin{tabular}{lllll}
\hline & Volatility & $r e r_{t}$ & $y_{t}$ & $p_{t}$ \\
\hline Period 6 & $86 \%$ & $19 \%$ & $14 \%$ & $45 \%$ \\
& $(0.02)$ & $(0.10)$ & $(0.07)$ & $(0.11)$ \\
Period 12 & $87 \%$ & $17 \%$ & $13 \%$ & $48 \%$ \\
& $(0.02)$ & $(0.10)$ & $(0.07)$ & $(0.09)$ \\
Period 18 & $86 \%$ & $17 \%$ & $13 \%$ & $47 \%$ \\
& $(0.03)$ & $(0.10)$ & $(0.07)$ & $(0.10)$ \\
Period 24 & $85 \%$ & $16 \%$ & $13 \%$ & $47 \%$ \\
& $(0.03)$ & $(0.10)$ & $(0.07)$ & $(0.10)$ \\
\hline
\end{tabular}

Numbers in parentheses report the standard errors.

One could argue that the variables used to assess the exchange rate risk might be misleading. Thus, the exchange rate risk was measured with the moving standard deviation with three-monthly window as in Table 1. Figure 7 and Table 5 report the impulse response functions and forecast error variance decompositions with this measure. The results remain robust.

A decrease in the CBRTs foreign exchange liabilities might be mimicking the decrease in money supply in the market. Therefore, the estimates report the effect of the tight monetary policy but not the exchange rate risk. In order to account for that, reserve money is included as the first variable in the VAR specification. These results are not elaborated on here but are reported in Appendix B. Overall, the basic conclusion was robust.

\section{CONCLUSION}

This study assesses the effect of exchange rate risk for a small open developing economy: Turkey. To measure the exchange rate risk, three measures were used from the CBRTs balance sheet: the ratio of the total foreign exchange liabilities to (1) the total reserves, (2) the CBRTs reserves and (3) the Turkish lira liabilities. This way of measuring has some advantages to other econometrically heavy measures. First, these variables directly mea- sure the strength of the CBRT to stabilize the real exchange rate. Second, these variables are directly observable by the public; and third, they are not subject to specification tests like the one in econometric models. The empirical evidence provided in this paper is parallel to the economic priors as outlined in Appendix A. The higher exchange rate risk is associated with a depreciation of the local currency, an increase in prices and a decrease in output.

\section{REFERENCES}

Agénor, P.-R. and Montiel, P. J. (1999) Development Macroeconomics, 2nd edn, Princeton University Press, Princeton, NJ.

Berument, H. (forthcoming) Measuring monetary policy for a small open economy: Turkey, Journal of Macroeconomics.

Berument, H. and Gunay, A. (2003) Exchange rate risk and interest rate: a case study of Turkey, Open Economies Review, 14, 19-27.

Berument, H. and Pasaogullari, M. (2003) Effects of the real exchange rate on output and inflation: evidence from Turkey, Developing Economies, 41(4), 401-35.

Bleaney, M. and Greenaway, D. (2001) The impact of trade and real exchange rate volatility on investment and growth in Sub-Saharan Africa, Journal of Development Economics, 65, 491-500.

Bomberger, W. (1996) Disagreement as a measure of uncertainty, Journal of Money, Credit and Banking, 28, 381-92.

Cote, A. (1994) Exchange rate volatility and trade: a survey, Bank of Canada Working Paper, no. 5.

Davis, G. and Kanogo, B. (1996) On measuring the effect of inflation uncertainty on real GNP growth, Oxford Economic Papers, 48, 163-75.

Felmingham, B. and Mansfield, P. (1997) Rationality and the risk premium on the Australian dollar, International Economic Journal, 11, 47-57.

Hafer, R. W. (1986) Inflation uncertainty and a test of the Friedman hypothesis, Journal of Macroeconomics, 18, 365-72.

Kamin, S. B. (1996) Exchange rates and inflation in exchange-rate based stabilizations: an empirical examination, International Finance Discussion Paper, 554, Board of Governors of the Federal Reserve System, Washington, DC.

Kamin, S. B. and Rogers, J. H. (2000) Output and the real exchange rate in developing countries: an application to Mexico, Journal of Development Economics, 61, 85-109.

Strongin, S. (1995) The identification of monetary policy disturbances explaining the liquidity puzzle, Journal of Monetary Economics, 35, 463-97.

Tai, C. (2000) Time-varying market, interest rate, and exchange rate risk premia in the US commercial bank stock returns, Journal of Multinational Financial Management, 10, 397-420.

\section{APPENDIX A: AN ILLUSTRATIVE MODEL ${ }^{5}$}

Total GDP, $Y$, is divided into two components; domestic demand, DD and net exports, NX in Equation A1:

\footnotetext{
${ }^{5}$ This appendix starts with the Kamin and Rogers (2000) model and extends it by considering the effect of exchange rate risk.
} 

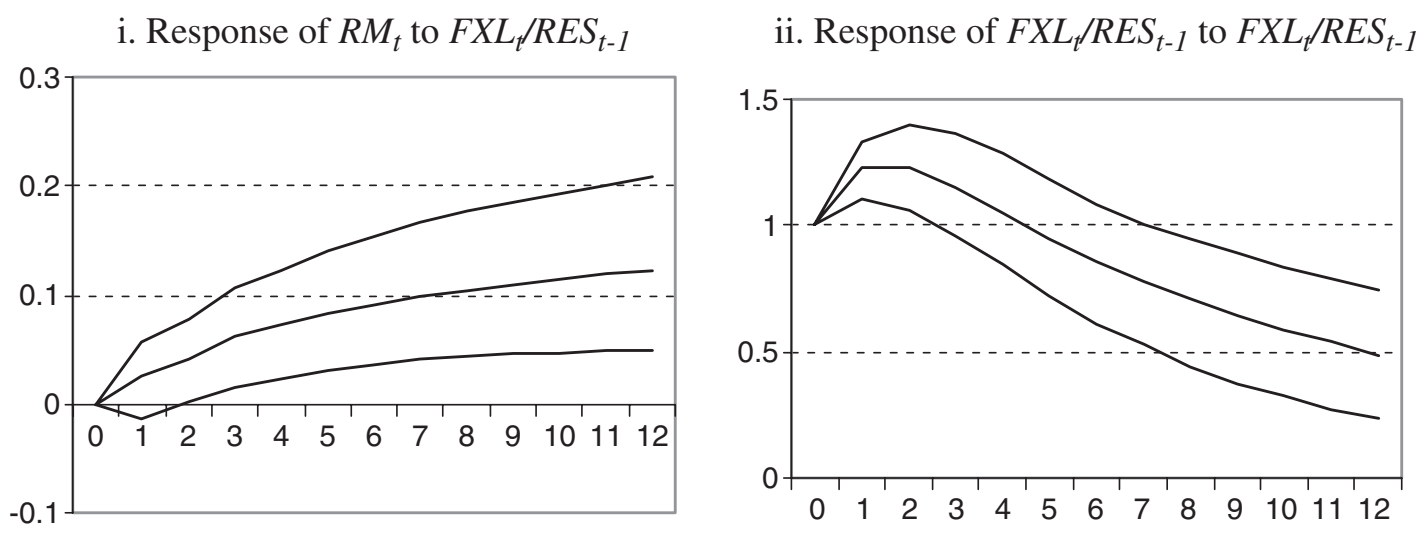

iii. Response of $r e r_{t}$ to $F X L_{t} / R E S_{t-1}$

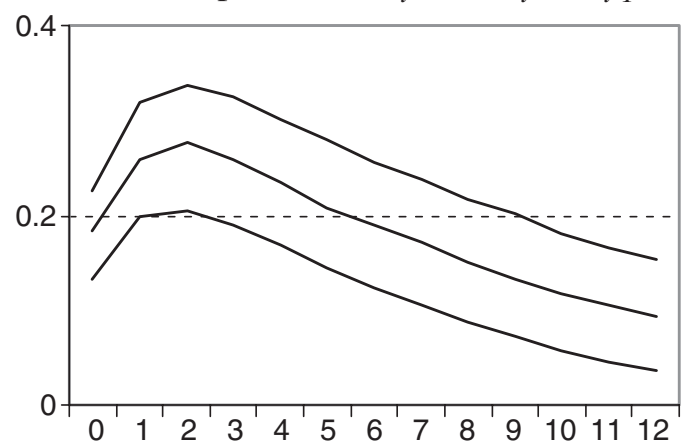

iv. Response of $y_{t}$ to $F X L_{t} / R E S_{t-1}$

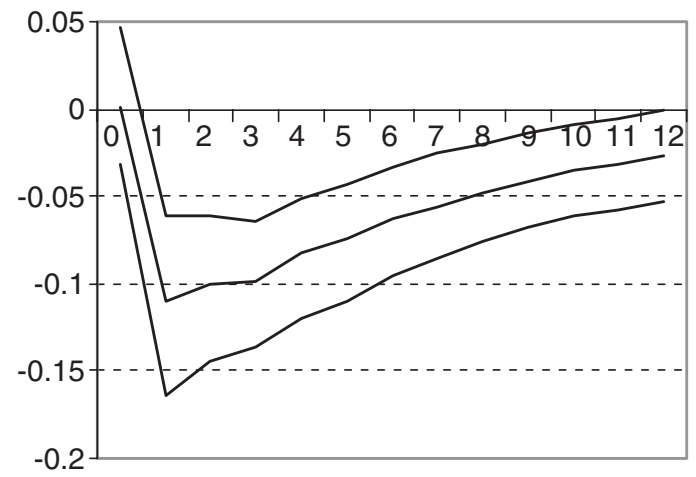

v. Response of $p_{t}$ to $F X L_{t} / R E S_{t-1}$

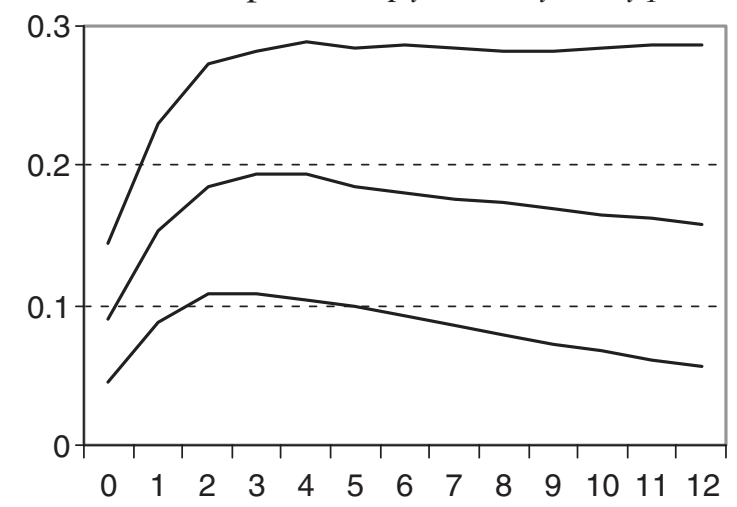

Fig. B1. Impulse response functions

$$
Y=\mathrm{DD}+\mathrm{NX}
$$

In Equation A2, net export is related positively to the real exchange rate, rer (defined so that an increase indicates depreciation), negatively to output, $Y$ and real exchange rate risk, $\sigma$ :

$$
\mathrm{NX}=a_{21} r e r-a_{22} Y-a_{23} \sigma
$$

There is a long list in the literature explaining the variables that affect the domestic demand in Equation A3: real interest rate $r$, fiscal deficit FISCDEF, the stock of real bank credit RCREDIT, the nominal interest rate $i$, the

inflation rate $\Pi$, the real exchange rate rer and the real wage RW. As the real exchange rate affects net exports positively, additional effects on aggregate demand are assumed negative:

$$
\begin{aligned}
\mathrm{DD}= & -a_{31} r+a_{32} \mathrm{FISCDEF}+a_{33} \mathrm{RCREDIT} \\
& -a_{34} i-a_{35} \Pi-a_{36} r e r+a_{37} \mathrm{RW}
\end{aligned}
$$

In Equation A4 the supply of bank credit is explained by the bank's main sources of funds, real domestic money, $\mathrm{RM}$, and borrowing from abroad proxied by capital flows KA: 
i. Response of $R M_{t}$ to $F X L_{t} / T R E S_{t-1}$

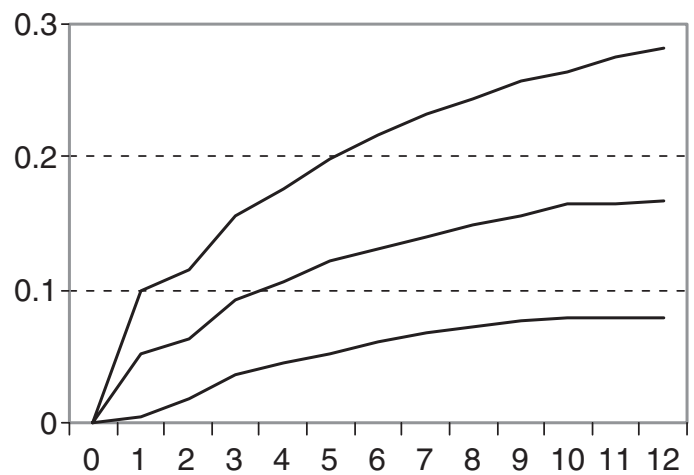

iii. Response of $r e r_{t}$ to $F X L_{t} / T R E S_{t-1}$
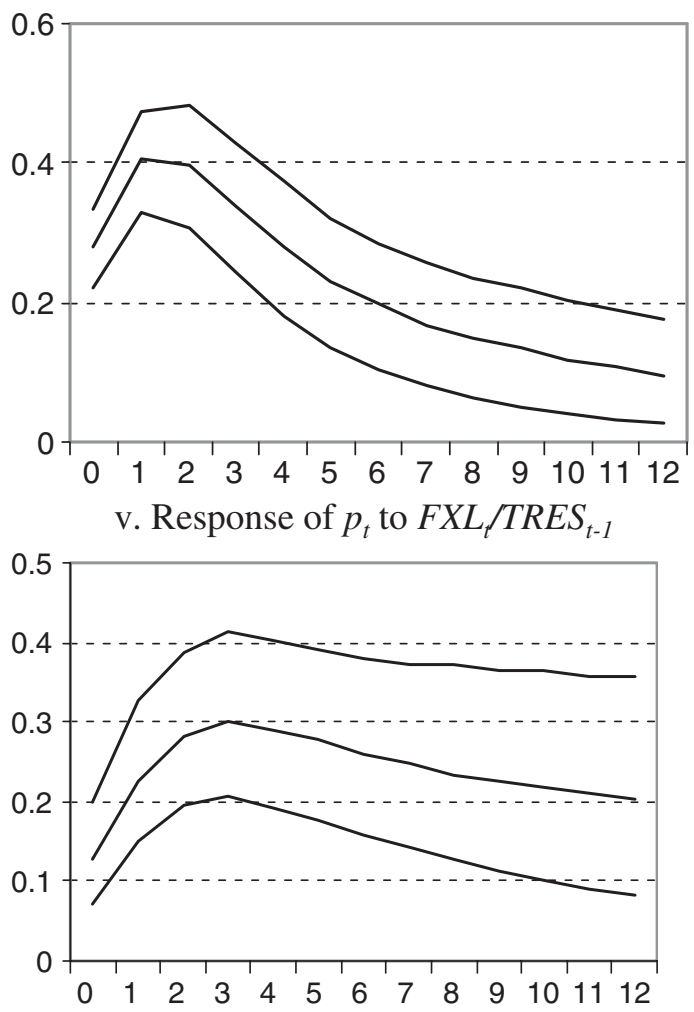

Fig. B2. Impulse response functions

$$
\mathrm{RCREDIT}=a_{41} \mathrm{RM}+a_{42} \mathrm{KA}
$$

The standard money demand equation is given in Equation A5:

$$
\mathrm{RM}=a_{51} Y-a_{52} i-a_{53} \sigma
$$

The central bank's reaction function for the nominal interest rate includes inflation $\Pi$, output $Y$, capital flows $\mathrm{KA}$, and real exchange rate risk $\sigma$.

$$
i=a_{61} \Pi+a_{62} Y-a_{63} \mathrm{KA}+a_{64} \sigma
$$

ii. Response of $F X L_{t} / T R E S_{t-1}$ to $F X L_{t} / T R E S_{t-1}$

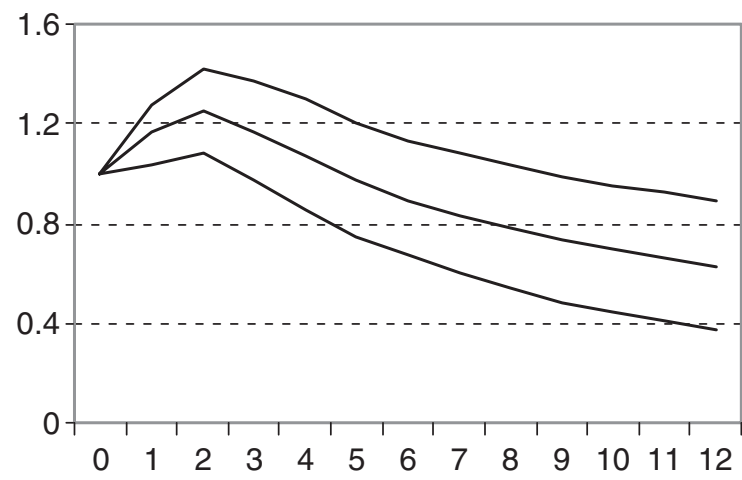

iv. Response of $y_{t}$ to $F X L_{t} / T R E S_{t-1}$

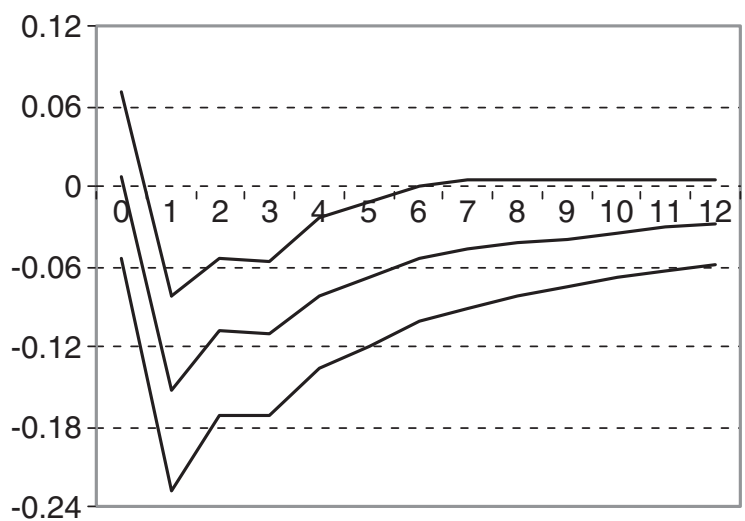

Equation A7 presents the CPI inflation rate as in Kamin (1996). It is determined by inflation $\Pi$, output $Y$ and the rate of nominal exchange rate $E^{\prime}$.

$$
\Pi=a_{71} r e r+a_{72} Y+a_{73} E^{\prime}
$$

Equation A8 is the interest parity condition. Net capital flows KA is determined by nominal interest rate $i$, the rate of nominal exchange rate $E,{ }^{\prime}$ US interest rate $i^{\mathrm{US}}$ and the real exchange rate risk $\sigma$.

$$
\mathrm{KA}=a_{81} i-a_{82} E^{\prime}-a_{83} i^{\mathrm{US}}-a_{84} \sigma
$$


i. Response of $R M_{t}$ to $F X L_{t} / T L L_{t-1}$

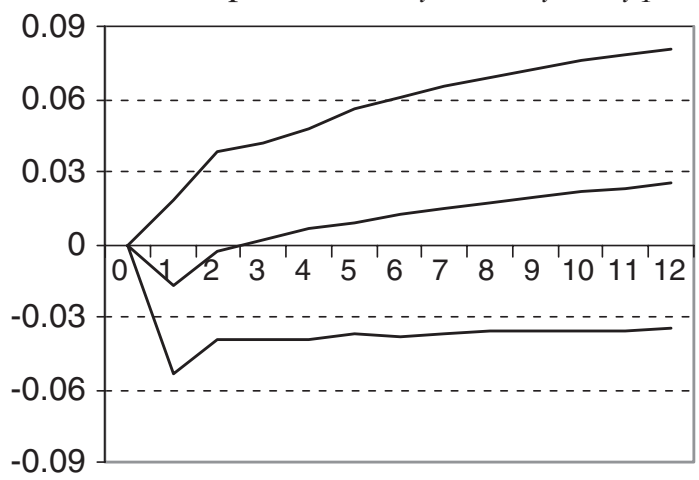

iii. Response of $r e r_{t}$ to $F X L_{t} / T L L_{t-1}$
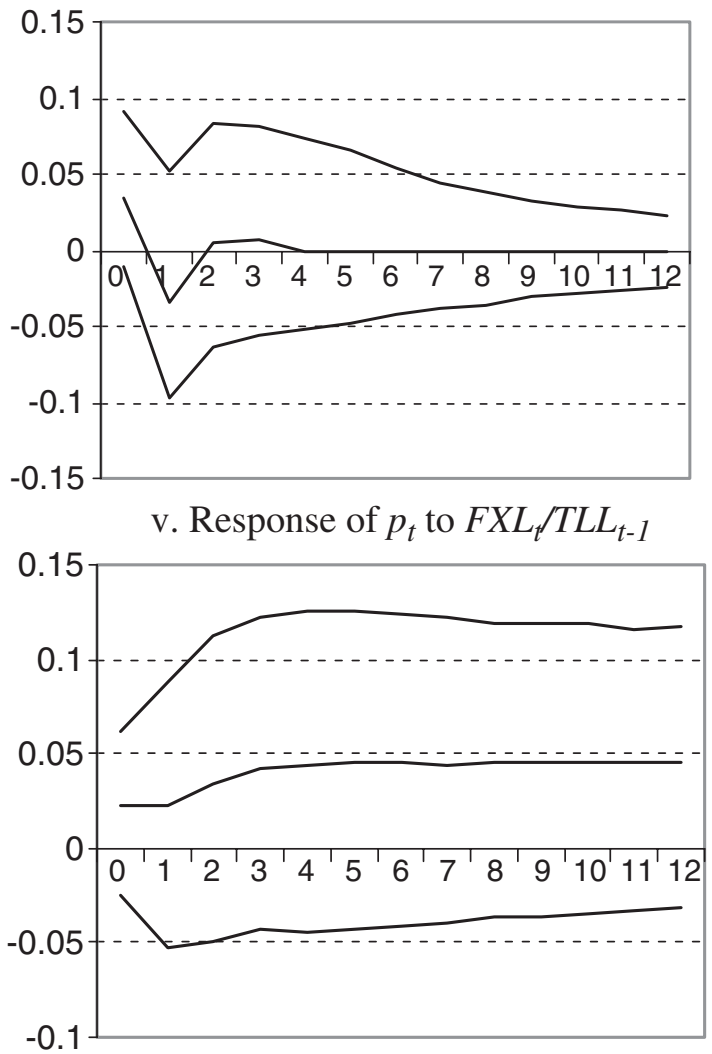

Fig. B3. Impulse response functions

In Equation A9, exchange rate depreciation is a function of domestic inflation $\Pi$, foreign inflation $\Pi^{\mathrm{US}}$, real exchange rate $r e r$ and the real exchange rate risk $\sigma$.

$$
E^{\prime}=a_{91} \Pi-a_{92} \Pi^{\mathrm{US}}+a_{93} r e r+a_{95} \sigma
$$

In Equation A10 the real exchange rate is determined by the balance of payment pressures and the real exchange rate risk.

$$
r e r=-a_{101} \mathrm{NX}-a_{102} \mathrm{KA}+a_{103} \sigma
$$

ii. Response of $F X L_{t} / T L L_{t}$ to $F X L / T L L_{t-1}$
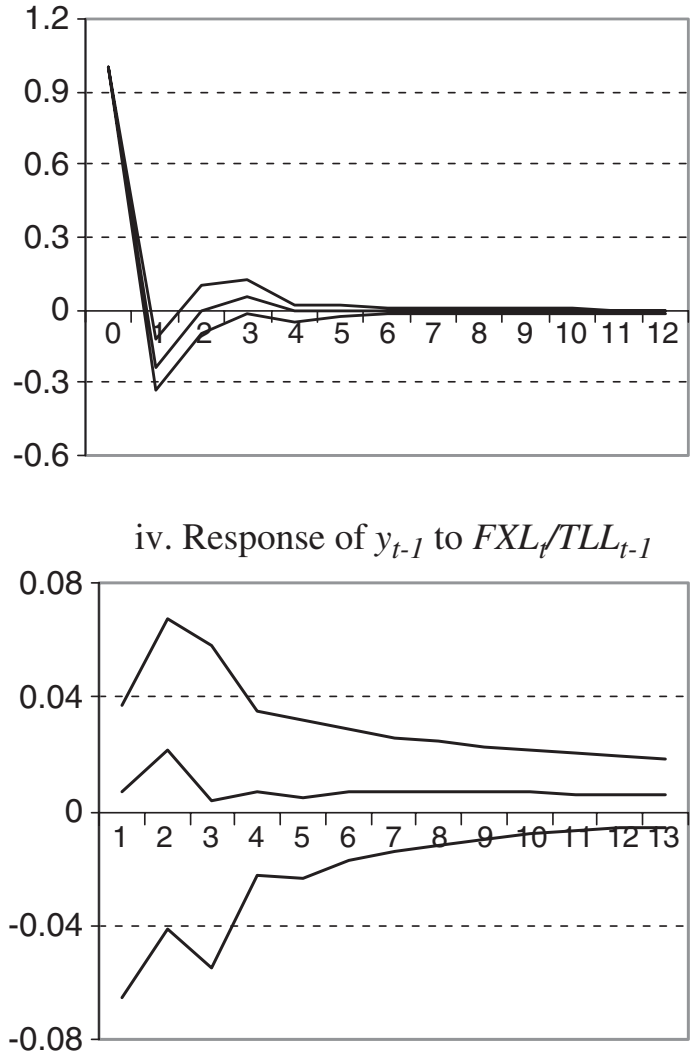
Table B1. Forecast error variance decompositions: contribution of $F X L_{t} / R E S_{t-1}$ to changes in key macroeconomic variables

\begin{tabular}{llllll}
\hline & $R M_{t}$ & $F X L_{t} /$ RES $_{t-1}$ & rer $_{t}$ & $y_{t}$ & $p_{t}$ \\
\hline Period 6 & $6 \%$ & $85 \%$ & $49 \%$ & $14 \%$ & $28 \%$ \\
& $(0.06)$ & $(0)$ & $(0.06)$ & $(0.05)$ & $(0.08)$ \\
Period 12 & $13 \%$ & $78 \%$ & $51 \%$ & $16 \%$ & $27 \%$ \\
& $(0.09)$ & $(0)$ & $(0.04)$ & $(0.05)$ & $(0.09)$ \\
Period 18 & $16 \%$ & $72 \%$ & $49 \%$ & $16 \%$ & $25 \%$ \\
& $(0.10)$ & $(0)$ & $(0.02)$ & $(0.05)$ & $(0.09)$ \\
Period 24 & $17 \%$ & $68 \%$ & $47 \%$ & $15 \%$ & $23 \%$ \\
& $(0.10)$ & $(0.01)$ & $(0.02)$ & $(0.05)$ & $(0.10)$ \\
\hline
\end{tabular}

Numbers in parentheses report the standard errors.

Table B2. Forecast error variance decompositions: contribution of $F X L_{t} /$ TRES $_{t-1}$ to changes in key macroeconomic variables

\begin{tabular}{llllll}
\hline & $R M_{t}$ & $F X L_{t} /$ TRES $_{t-1}$ & rer $_{t}$ & $y_{t}$ & $p_{t}$ \\
\hline Period 6 & $8 \%$ & $85 \%$ & $45 \%$ & $8 \%$ & $36 \%$ \\
& $(0.07)$ & $(0.01)$ & $(0.05)$ & $(0.04)$ & $(0.07)$ \\
Period 12 & $16 \%$ & $80 \%$ & $45 \%$ & $9 \%$ & $32 \%$ \\
& $(0.09)$ & $(0.00)$ & $(0.03)$ & $(0.05)$ & $(0.06)$ \\
Period 18 & $19 \%$ & $77 \%$ & $43 \%$ & $10 \%$ & $29 \%$ \\
& $(0.09)$ & $(0.00)$ & $(0.02)$ & $(0.04)$ & $(0.07)$ \\
Period 24 & $20 \%$ & $75 \%$ & $42 \%$ & $10 \%$ & $26 \%$ \\
& $(0.08)$ & $(0.00)$ & $(0.02)$ & $(0.05)$ & $(0.07)$ \\
\hline
\end{tabular}

Numbers in parentheses report the standard errors.

$$
\mathrm{RW}=a_{121} Y-a_{122} \Pi
$$

By substituting the endogenous variables, the 12-equation system reduces to a 3 -equations system that we call the core model:

$$
\Pi=a_{11^{\prime}} r e r-a_{12^{\prime}} Y-a_{13^{\prime}} \Pi^{\mathrm{US}}+a_{14^{\prime}} \sigma
$$

Table B3. Forecast error variance decompositions: contribution of $F X L_{t} / T L L_{t-1}$ to changes in key macroeconomic variables

\begin{tabular}{llllll}
\hline & $R M_{t}$ & $F X L_{t} / T L L_{t-1}$ & rer $_{t}$ & $y_{t}$ & $p_{t}$ \\
\hline Period 6 & $1 \%$ & $70 \%$ & $1 \%$ & $1 \%$ & $2 \%$ \\
& $(0.02)$ & $(0.06)$ & $(0.02)$ & $(0.02)$ & $(0.06)$ \\
Period 12 & $1 \%$ & $69 \%$ & $1 \%$ & $1 \%$ & $2 \%$ \\
& $(0.03)$ & $(0.06)$ & $(0.02)$ & $(0.02)$ & $(0.07)$ \\
Period 18 & $1 \%$ & $69 \%$ & $1 \%$ & $1 \%$ & $2 \%$ \\
& $(0.04)$ & $(0.06)$ & $(0.02)$ & $(0.02)$ & $(0.07)$ \\
Period 24 & $2 \%$ & $69 \%$ & $1 \%$ & $1 \%$ & $3 \%$ \\
& $(0.05)$ & $(0.06)$ & $(0.02)$ & $(0.02)$ & $(0.07)$ \\
\hline
\end{tabular}

Numbers in parentheses report the standard errors.

$$
\begin{aligned}
r e r= & a_{21^{\prime}} Y-a_{22^{\prime}} \Pi-a_{23^{\prime}} i^{\mathrm{US}}-a_{24^{\prime}} \Pi^{\mathrm{US}}-a_{25^{\prime}} \sigma \\
Y= & a_{31^{\prime}} i-a_{32^{\prime}} r+a_{33^{\prime}} \Pi^{\mathrm{US}}+a_{34^{\prime}} \Pi \\
& -a_{35^{\prime}} i^{\mathrm{US}}-a_{36^{\prime}} r e r+a_{37^{\prime}} \sigma
\end{aligned}
$$

When these three equations are analysed, it is possible to observe the effects of exchange rate risk on the economy. These effects may be captured by the signs of risk in these three equations. The first equation (the equation for inflation) $a_{14^{\prime}}$ is positive if $a_{73} \cdot a_{91}>1$, so that inflation increases with the increasing exchange rate risk. In the second equation, the real exchange rate depreciates with increasing risk, i.e. $a_{25^{\prime}}$ is positive if $\left(a_{101} \cdot a_{23}+a_{102}\right.$. $\left.a_{82} \cdot a_{94}+a_{102} \cdot a_{84}\right)>\left(a_{102} \cdot a_{81} \cdot a_{64}\right)$. In the third equation, output always decreases with increasing risk, $a_{37}$ is always negative independent of any conditions. 